\title{
ANL/ET/CP--91637 CONF-970111--7
}

USE OF INDENTATION TECHNIQUE TO MEASURE ELASTIC MODULUS OF PLASMASPRAYED ZIRCONIA THERMAL BARRIER COATING*

J. P. Singh, M. Sutaria, and M. Ferber ${ }^{\#}$

Energy Technology Division

Argonne National Laboratory

Argonne, IL 60439

\#Oak Ridge National Laboratory

Oak Ridge, TN 37831

3FCFIVED

MAR 25 1997

OSTI

January 1997

\begin{abstract}
The submitted manuscript has been created by the University of Chicago as Operator of Argonne National Laboratory ("Argonne") under Contract No. W-31-109-ENG-38 with the U.S. Department of Energy. The U.S. Government retains for itself, and others acting on its behalf, a paid-up, nonexclusive, irrevocable worldwide license in said article to reproduce, prepare derivative works, distribute copies to the public, and periorm publicly and display publicly, by or on behalf of the Government.
\end{abstract}

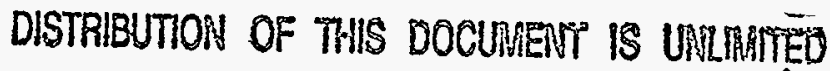

For publication in Proceedings of 21st Annual Conference \& Exposition on Composites, Advanced Ceramics, Material and Structure, American Ceramic Society, Cocoa Beach, Florida, January 12-16, 1997.

*Research sponsored by the Office of Industrial Technologies, U.S. Department of Energy (DOE), under Contract W-31-109-Eng-38. 


\section{DISCLAMMER}

Portions of this doenment may be illegible in electronic-inage products Images=areproduced from the best available original document. 
USE OF INDENTATION TECHNIQUE TO MEASURE ELASTIC MODULUS OF PLASMA-SPRAYED ZIRCONIA THERMAL BARRIER COATING

\author{
J. P. Singh, M. Sutaria, and M. Ferber ${ }^{\#}$ \\ Energy Technology Division, Argonne National Laboratory, Argonne, 느 60439 \\ \#Oak Ridge National Laboratory, Oak Ridge, TN 37831
}

\begin{abstract}
Elastic modulus of an yttria partially stabilized zirconia (YSZ) thermal barrier coating (TBC) was evaluated with a Knoop indentation technique. The measured elastic modulus values for the coating ranged from $68.4 \pm 22.6 \mathrm{GPa}$ at an indentation load of $50 \mathrm{~g}$ to $35.7 \pm 9.8$ at an indentation load of $300 \mathrm{~g}$. At higher loads, the elastic modulus values did not change significantly. This steady-state value of $35.7 \mathrm{GPa}$ for $\mathrm{ZrO}_{2} \mathrm{TBC}$ agreed well with literature values obtained by the Hertzian indentation method. Furthermore, the measured elastic modulus for the $\mathrm{TBC}$ is lower than that reported for bulk $\mathrm{ZrO}_{2}(\approx 190 \mathrm{GPa})$. This difference is believed to be due to the presence of a significant amount of porosity and microcracks in the TBCs.
\end{abstract}

\title{
INTRODUCTION
}

Thermal barrier coatings (TBCs) have shown great potential for increasing turbine inlet-gas temperature by reducing heat transfer from hot gas to air-cooled blades. Turbine superalloys melt in the range of $1230-1315^{\circ} \mathrm{C}$ [1]. Because the combustion gas environment is at $\approx 1370^{\circ} \mathrm{C}$, the superalloys are air-cooled to protect them from the oxidation, creep, melting, and thermal fatigue that reduces efficiency. Efficiency is traditionally improved by improving the design of the cooling system. An alternative approach is the use of TBCs. A typical TBC system consists of an insulating outer ceramic layer and an inner metallic "bond coat" layer between the ceramic layer and the metallic substrate. TBCs provide improved performance and 
increased efficiency by lowering the metal temperature and reducing the cooling air requirements [2-4].

However, premature failure of the ceramic coating layer is a concern for the reliability and long service life of gas turbine components [5-7]. Such failure of ceramic coatings may be related to factors such as residual stresses developed in the ceramic layer during cooling because of the expansion mismatch between the ceramic and the metallic layers [5-9]; cyclic inelastic strain in the coating due to thermal cycling during service [10-11]; as well as oxidation, plastic deformation and creep of the bond layer, and phase transformation and sintering of the top layer.

Many of these causes (especially those that are stress-related) are greatly influenced by the elastic modulus of the coating. Therefore, the elastic modulus becomes a critical parameter to be evaluated for improved understanding and prediction of TBC failure.

Conventional techniques used for bulk ceramics have been used to measure elastic moduli of $\mathrm{ZrO}_{2}$ coatings with limited success. These techniques consist primarily of loading coated specimens in uniaxial tension or flexural mode and then estimating the elastic modulus from load-deflection plots. Inconsistent results observed in many cases have been attributed to the errors introduced in measurements because of the small thickness of coating samples. To this end, measurement of elastic modulus by an indentation technique offers great promise [12-14].

In a recent study [12], Hertzian indentation testing has been used to generate contact damage in plasma sprayed ceramic coatings and subsequently the measurements were made to evaluate elastic modulus of the coatings. In addition, Knoop indentation testing $[13,14]$ has been used to measure elastic modulus of bulk ceramics. This method is based on measurement of elastic recovery of surface impression of the indentation diagonals ( $a$ and $b$ ) made by the Knoop indenter, as shown in Fig. 1. The elastic recovery is independent of load and is correlated with hardness $(\mathrm{H})$ to elastic modulus $(\mathrm{E})$ ratio as follows:

$$
\frac{\mathrm{b}^{\prime}}{\mathrm{a}^{\prime}}=\frac{\mathrm{b}}{\mathrm{a}}-\alpha \frac{\mathrm{H}}{\mathrm{E}},
$$

where $a^{\prime}$ and $b^{\prime}$ are the dimensions of the Knoop diagonals after elastic recovery, and $\alpha$ is a constant. The value of $\alpha$ was determined as 0.45 by curve-fitting the 
experimental data to Eq. 1. In the equation, values of $a, b, a^{\prime}$, and $b^{\prime}$ can be obtained from Knoop indentations, and $\mathrm{H}$ can be measured by using Vickers indentation [15,16] to estimate E. As indicated by Marshall et. al. [13], the relative error in the estimation of $\mathrm{H} / \mathrm{E}$ is $<10 \%$ for mostbuttle materials. =

The purpose of this study is to demonstrate the applicability of Knoop indentation testing for the measurements of elastic modulus of ceramic coatings and compare the results with those obtained by other techniques (especially Hertzian indentation testing).

\section{EXPERIMENTAL PROCEDURES}

\section{Material}

The TBC sample consisted of substrate bars machined by electro-discharge machining (EDM) from 1.0 in. round stock of Waspaloy, supplied by Teledyne Allvac/Vasco. The alloy composition (in wt.\%) was Ni-58.6, Cr-19.3, Co-12.5, Mo-3.9, Ti-2.93, Al-1.4, Fe-1.1, Zr-0.07, Cb(Nb)-0.06, Si-0.06, Mn-0.04, Ta$0.03, \mathrm{Cu}-0.02, \mathrm{~S}-0.0003, \mathrm{C}-0.006, \mathrm{P}-0.005$. One face of the substrate bar was grit-blasted (24 grit $\mathrm{Al}_{2} \mathrm{O}_{3}$ at 70 psi), after which the specimen was cleaned ultrasonically in methanol. The substrate was first coated with 5 mil of NiCrAlY and subsequently with $\approx 10$ mils of yttria partially stabilized zirconia (YSZ) by air plasma spraying. The $\mathrm{YSZ}$ powder contained 7-9 wt\% $\mathrm{Y}_{2} \mathrm{O}_{3}$. A typical photomicrograph of the polished cross-section of the TBC is shown in Fig. 2; significant porosity in the zirconia top coat $(180 \mu \mathrm{m})$ is clearly evident.

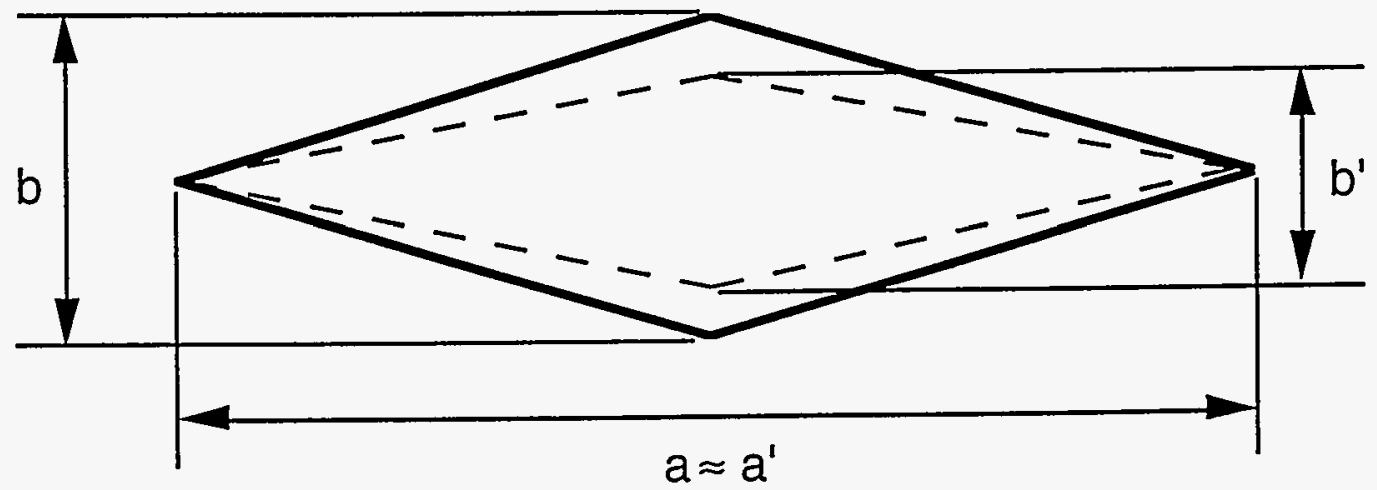

Fig. 1. Schematic showing elastic recovery of a Knoop indentation. 


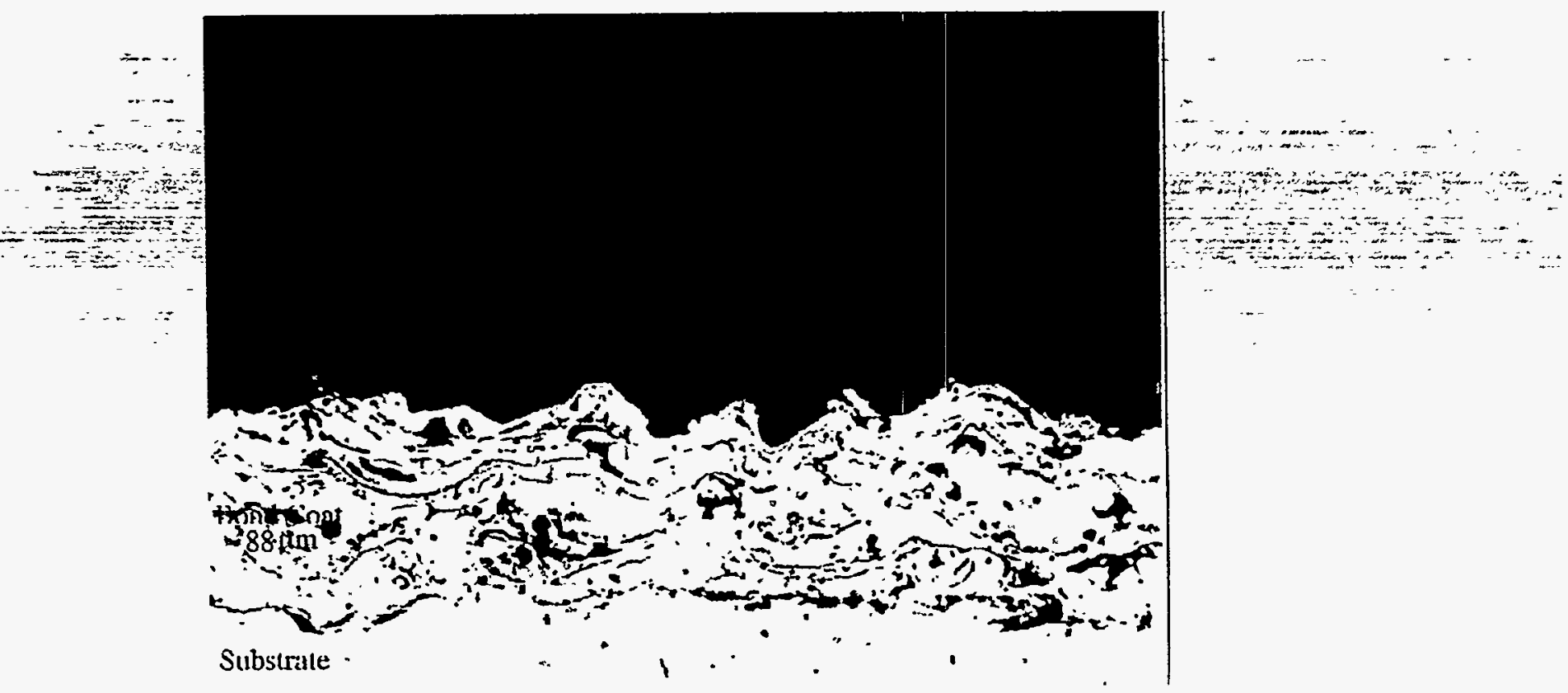

Fig. 2. Photomicrograph of typical polished cross section of TBC.

Indentation Testing

First, the sample was fine-polished $(0.5 \mu \mathrm{m})$ and then its hardness $(\mathrm{H})$ was measured at various positions using a Vickers indenter. The hardness was calculated by Equation 2, as shown below:

$$
\mathrm{H}=1854.4 \frac{\mathrm{F}}{\mathrm{d}^{2}},
$$

where $\mathrm{F}$ is the indentation load $(\mathrm{g})$ and $\mathrm{d}$ is the indentation diagonal $(\mathrm{mm})$. Indentations were made at 50,100,300, and $500 \mathrm{~g}$ loads, and the loading time was kept constant at $15 \mathrm{~s}$ for all indentations. Thirty to forty indentations were made for each condition to obtain a statistically reliable value.

Subsequently, the surface was fine-polished and Knoop indentations were made at the same locations with identical loads and times as mentioned above. The Knoop indentation diagonals (as shown in Fig. 3) were carefully measured with a highmagnification optical microscope. Elastic recovery $\left(b^{\prime} / a^{\prime}-b / a\right)$ was evaluated with a known value of $a / b$ (7.11) for the Knoop indenter geometry, and elastic moduli were calculated by Eq. 1 . 


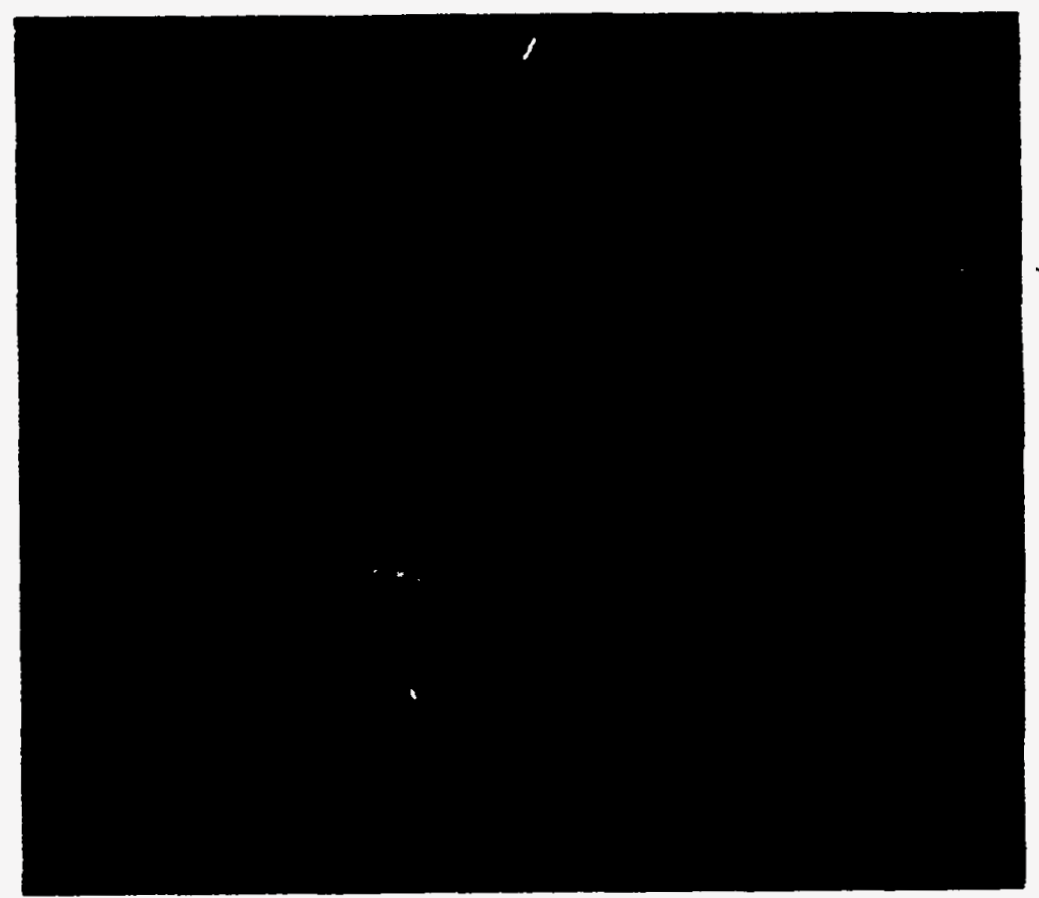

Fig. 3. Photomicrograph of typical Knoop indentation.

\section{RESULTS AND DISCUSSION}

Figure 4 shows the variation of hardness with indentation load. Hardness decreases from $6.1 \mathrm{GPa}$ at an indentation load of $50 \mathrm{~g}$ to $3.3 \mathrm{GPa}$ at an indentation load of $300 \mathrm{~g}$. At a higher load of $500 \mathrm{~g}$, hardness appears to approach a steady state intrinsic value of $1.8 \mathrm{GPa}$. Similar dependence of hardness was also observed by Hirao and Tomozáwa [17] for vitreous silica and by Swain and Bradt [18] for yttrium and aluminum garnet. Several models have been proposed to explain this dependence. Recently, $\mathrm{Li}$ and Bradt [19] explained this dependence in terms of Newtonian-like proportional specimen resistance (PSR). According to this model, the effective indentation test load is equal to the applied indentation load minus PSR, where PSR increases with indentation load and size. The analysis also suggests a critical load below which hardness is load-dependent. Above the critical load, the hardness is independent of indentation load and relates to intrinsic hardness value. 


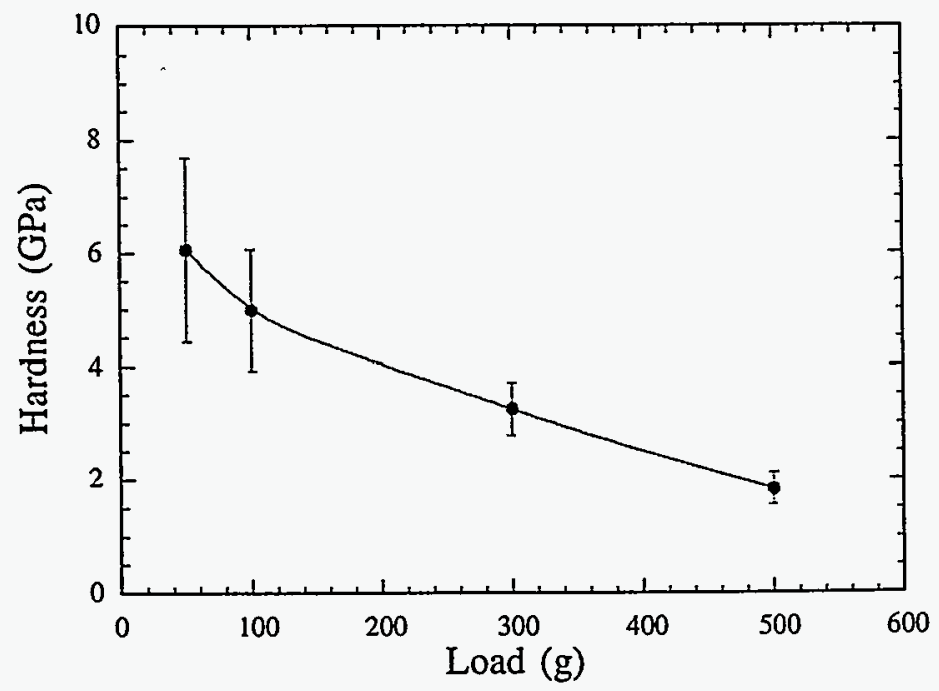

Fig. 4. Variation of hardness with indentation load.

Figure 5 shows the dependence of elastic modulus on indentation load; the elastic modulus decreases from $68.4 \pm 22.6 \mathrm{GPa}$ at an indentation load of $50 \mathrm{~g}$ to $35.4 \pm$ $13.4 \mathrm{GPa}$ at an indentation load of $500 \mathrm{~g}$. As expected, at lower loads the indentation encompasses only a relatively small region of the TBC. The indentation size is on the order of a single grain or a lamellae of $\mathrm{ZrO}_{2}$ coating. This minimizes the extent of defects (such as pores, grain/lamellae boundaries, microcracking, etc.) encompassed by the indentation, which results in observed higher elastic modulus values. On the other hand, at higher loads, the indentation size is large and encompasses many of the above-mentioned microstructural defects, as shown in Fig. 6. This results in the observed decrease in elastic modulus. After a critical load $(\approx 300 \mathrm{~g}$ in the present case), the extent of defects encountered per unit area or per unit volume by the indentation becomes relatively constant. Therefore, the resulting elastic modulus value becomes insensitive to the indentation load after the critical load is reached and this value can be used for materials selection and component design.

Table I compares the elastic modulus value obtained in the present study by Knoop indentation with that obtained by the Hertzian indentation method [12]. The elastic modulus value of $35 \mathrm{GPa}$ obtained by Knoop indentation agrees very well with the value of $30 \mathrm{GPa}$ obtained by Hertzian indentation. Also, the hardness value (1.8 GPa) obtained by Vickers indentation method in the present study is the same as that obtained by Pajares et al. [12]. 


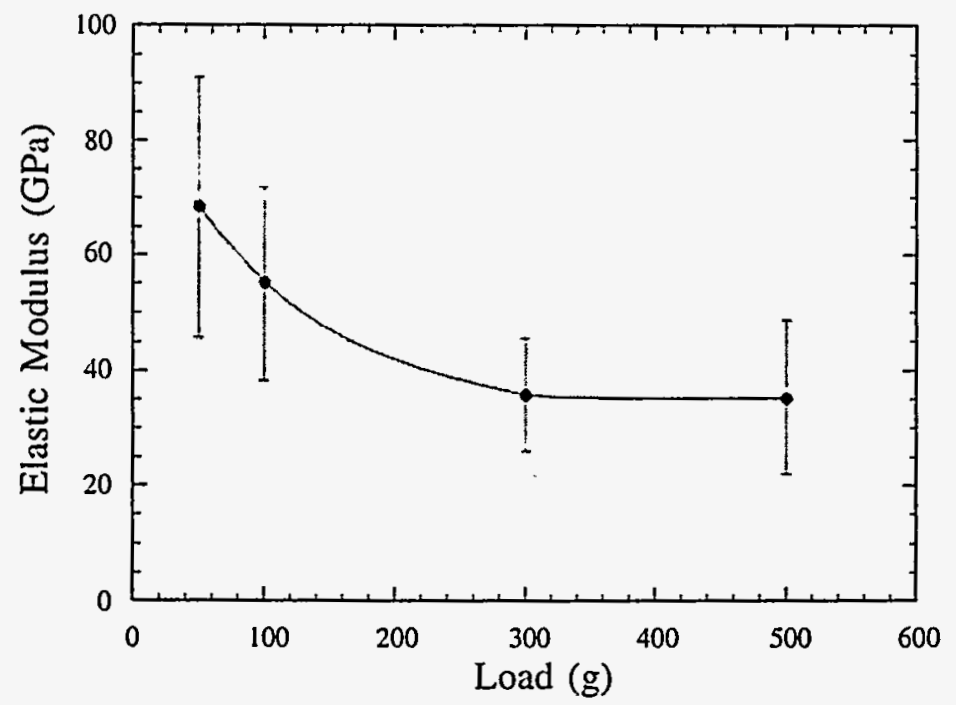

Fig. 5. Dependence of elastic modulus on indentation load.

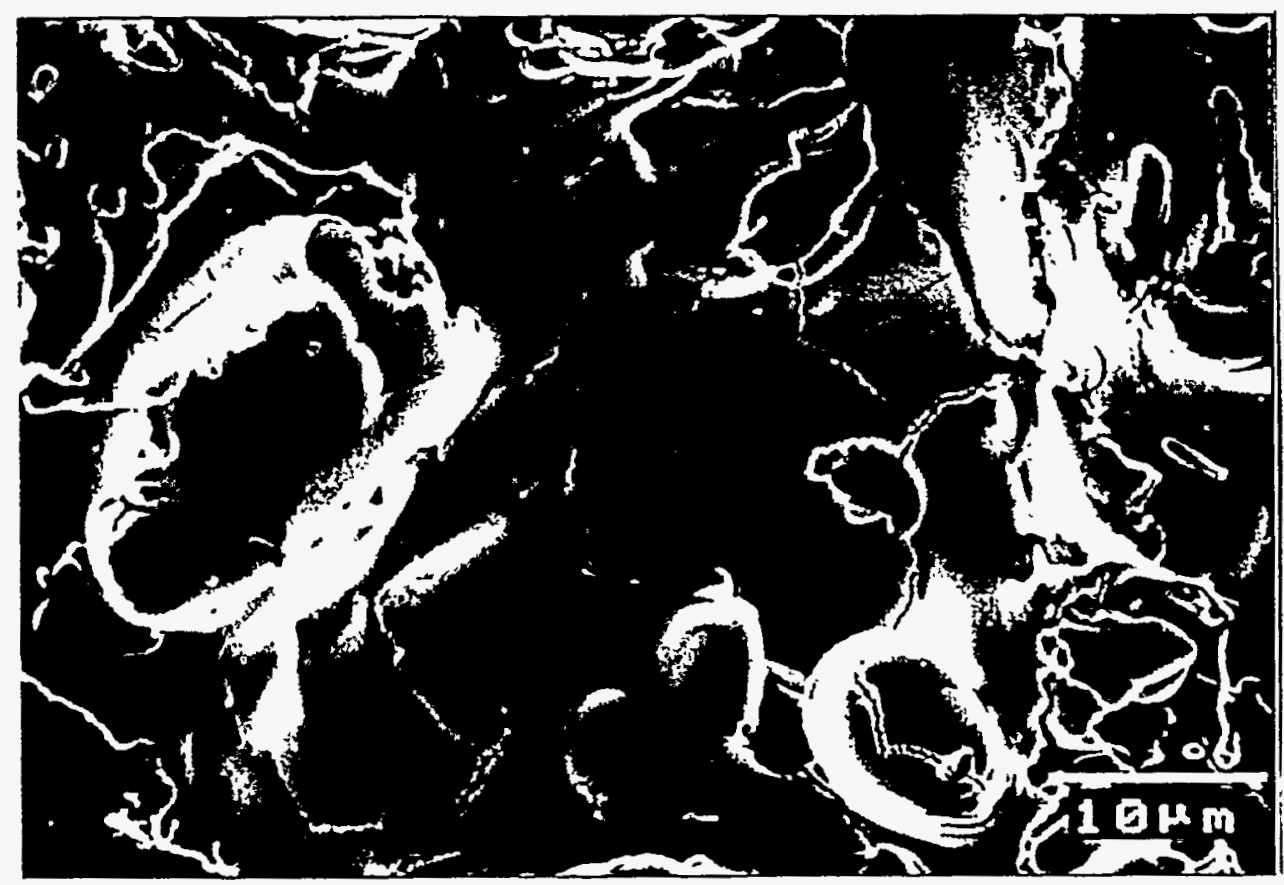

Fig. 6. Typical photomicrograph of $\mathrm{ZrO}_{2}$ coating showing microstructural defects such as microcracks and porosity. 
Table I. Comparison of elastic moduli resulting from Knoop and Hertzian indentation methods

\begin{tabular}{lc}
\hline \multicolumn{1}{c}{ Testing Method } & $\begin{array}{c}\text { Elastic Modulus } \\
\text { (GPa) }\end{array}$ \\
\hline Knoop indentation & $35 \pm 13$ \\
Hertzian indentation [12] & $30 \pm 6$ \\
\hline
\end{tabular}

It is also to be noted that the measured elastic modulus values $(\approx 40-65 \mathrm{GPa})$ for the $\mathrm{ZrO}_{2} \mathrm{TBC}$ are much lower than those reported for fully dense bulk $\mathrm{ZrO}_{2}$ $(\approx 190 \mathrm{GPa})$. This difference is due to the presence of significant porosity and microcrack [20], as shown in Fig. 6.

\section{CONCLUSIONS}

The hardness and elastic modulus of $\mathrm{ZrO}_{2}$ thermal barrier coating was measured by the Vickers and Knoop indentation techniques. Hardness and elastic modulus values decreased with increasing indentation load and approached a steady state value of 1.8 and $35 \mathrm{GPa}$, respectively, at an indentation load of $500 \mathrm{~g}$. These values agree very well with those measured by the Hertzian indentation method, demonstrating the applicability of Knoop and Vickers indentations for reliably measuring the elastic modului of thermal barrier coatings.

\section{ACKNOWLEDGMENTS}

This work is supported by the Office of Industrial Technologies, U.S. Department of Energy (DOE), under Contract W-31-109-Eng-38.

\section{REFERENCES}

1. S. M. Meier and D. K. Gupta, "The Evolution of Thermal Barrier Coatings in Gas Turbine Applications," J. Engineering for Gas Turbine and Power, Trans. ASME, 111, 301-305, 1989. 
2. D. L. Ruckle, "Plasma Sprayed Ceramic Coatings for Turbine Vane Platforms," Thin Solid Films, 73, 455, 1980.

3. R. A. Miller, S. R. Levine, and S. Stecura, "Thermal Barrier Coatings for Aircraft Gas Turbines," AIAA Paper No. 80-0302, 1980.

4. D. S. Duvall and D. L. Ruckle, "Ceramic Thermal Barrier Coatings for Turbine Engine Components," ASME Paper No. 82-GT-332, 1982.

5. R. A. Miller and C. E. Lowell, "Failure Mechanisms of Thermal Barrier Coatings Exposed to Elevated Temperature," Thin Solid Films, 99, 265, 1982.

6. S. J. Grisaffe and S. R. Levine, Proceedings of the First DOE/EPRI Conference on Advanced Materials for Alternate Fuel Capable Directly Fired Heat Engines, Castine, ME, 1979.

7. D. L. Ruckle, "Evaluation of Plasma Sprayed Ceramic Coatings for Turbine Engine Components," Thin Solid Films, 64, 327, 1979.

8. P. F. Becher, R. W. Rice, C. C. Wu, and R. L. Jones, "Factors in the Degradation of Ceramic Coatings for Turbine Alloys," Thin Solid Films, 53, 225, 1978.

9. S. Rangaswamy and H. Herman, "Thermal Expansion Study of PlasmaSprayed Oxide Coatings," Thin Solid Films, 73, 43, 1980.

10. J. T. DeMasi-Marcin, K. D. Sheffler, and S. Bose, "Mechanisms of Degradation and Failure in a Plasma-Deposited Thermal Barrier Coating," ASME Journal of Engineering for Gas Turbines and Power, 112, 521-526, 1990.

11. "Thermal Barrier Coating Life Prediction Model Development-Final Report, No. NASA CR-180807," Performed by General Electric Co., Cincinnati, $\mathrm{OH}$; Sponsored by National Aeronautics and Space Administration, Lewis Research Center, Cleveland, OH, Nov. 1988. 
12. A. Pajares, L. Wei, B. R. Lawn, N. P. Padture, and C. C. Berndt, "Mechanical Characterization of Plasma Sprayed Ceramic Coatings on Metal Substrates by Contact Testing," Materials Science and Engineering A, 208,158-165, 1996.

13. D. B. Marshall, T. Noma, and A. G. Evans, "A Simple Method for Determining Elastic-Modulus-to-Hardness Ratios using Knoop Indentation Measurements," Comm. Am. Ceram. Soc., 65 (10)C-175-C-176, 1982.

14. B. R. Lawn and V. R. Howes, "Elastic Recovery at Hardness Indentations," J. Mater. Sc., 16 (10) 2745-52, 1981.

15. A. G. Evans and E. A. Charles, "Fracture Toughness Determinations by Indentation," J. Am. Ceram. Soc., 59(7-8)371-72, 1976.

16. G. R. Anstis, P. Chantikul, B. R. Lawn, and D. B. Marshall, "A Critical Evaluation of Indentation Techniques for Measuring Fracture Toughness: I," J. Am. Ceram. Soc., 64(9)533-38, 1981.

17. K. Hirao and M. Tomozawa, "Microhardness of $\mathrm{SiO}_{2}$ Glass in Various Environments." J. Am. Ceram. Soc., 70(7)497-502, 1987.

18. M. V. Swain and R. C. Bradt, "Nano and Micro Hardnesses of Single Crystal Yttrium Aluminum Garnet (YAG) on the \{111\} Plane," Plastic Deformation of Ceramics, eds. R. C. Bradt, C. A. Brookes, and J. L. Routbort, Plenum Press, New York, 1995.

19. H. Li and R. C. Bradt, "The Indentation Load/Size Effect and the Measurement of the Hardness of Vitreous Silica," J. Non-Cryst. Solids, 146, 197-212, 1992.

20. D. P. H. Hasselman and J. P. Singh, "Analysis of Thermal Stress Resistance of Microcracked Brittle Ceramics," Ceram. Bull., 58(9), 856-60, 1979. 


\section{DISCLAIMER}

This report was prepared as an account of work sponsored by an agency of the United States Government. Neither the United States Government nor any agency thereof, nor any of their employees, make any warranty, express or implied, or assumes any legal liability or responsibility for the accuracy, completeness, or usefulness of any information, apparatus, product, or process disclosed, or represents that its use would not infringe privately owned rights. Reference herein to any specific commercial product, process, or service by trade name, trademark, manufacturer, or otherwise does not necessarily constitute or imply its endorsement, recommendation, or favoring by the United States Government or any agency thereof. The views and opinions of authors expressed herein do not necessarily state or reflect those of the United States Government or any agency thereof. 